\title{
Discussion on the Inheritance and Protection of Opera Art from the Perspective of New Media
}

\author{
He Tingyan
}

Hexi University, Zhangye City, Gansu, 734000

Keywords: new media art; opera art; photography; communication

\begin{abstract}
Drama is a very important intangible cultural heritage of China. It is the soul of traditional Chinese culture. It shows the characteristics of the Chinese nation and is a valuable asset left by the previous generation of artists. However, the development of the art of opera has problems in the inheritance of art, and there has a loss of art. Therefore, in view of this traditional art, it is necessary to take a powerful protection measures.
\end{abstract}

\section{Introduction}

In recent years, the digital media art has been developing at a high speed. New media technology has sprung up all over the world and has been widely applied in various fields such as education, culture, business and so on. The function of new technology and equipment is constantly improving, and the operation of the system is becoming more and more humanized. With the help of new media art, artists can improve their interaction and enrich their presentation [1].

\section{The protection of the art of opera in the new media era}

The essence of the image lies in the recording of things, and the integration of the static and dynamic picture language. The expression of image and text is different, and it is recorded with the aid of symbols, so it has the features of visual and image. Compared with the expression of the text, the image combines the visual elements and the auditory elements. With the rapid development of digital technology, people use more digital images to record their daily life.

Image can play a very important role in the protection and inheritance of opera art. Nowadays, the inheritance of Peking Opera has been hindered many times. The state has studied the image engineering of Beijing opera, so that the audio-visual recovery of many Beijing Opera is restored. In the recording of Peking Opera in the link, fully using the form of image, can Peking opera performances were reviewed, based on audiovisual equipment are relatively perfect, make the art image more plump, these images can be completely preserved, for learner reference[2].

The combination of static and dynamic images to record the art of opera. The art of opera needs the advanced means to pass the dynamic and static image in the inheritance. Static images mainly collect pictures, and record the wonderful moments of dramas. The pictures of the opera art are generally the stage pictures, and the images of the actors are fully displayed. The dynamic image is a comprehensive record of the opera art by means of a camera. Compared with the simple photography, it can record the overall manifestation of the opera, and it can show the complete recovery value.

Nowadays, with the advent of the digital age, digital cameras and cameras are widely used in people's lives. The cost is very high, and the operation is very convenient and the transmission efficiency is high. With the continuous improvement of the new technology, high quality images provide a good foundation for the creation of art. Photographers in the digital age are more familiar with the operation of digital camera equipment. They are more familiar with the research and creation of topics, and can improve the quality of images. And in the post production, the method of non-linear editing is adopted, and the image effect is very good. The development of opera art should be combined with the development of the times, and the new vitality can be added with the 
help of digital image technology[3].

Nowadays, in the transmission of image information, digital images and graphics display vitality. Image art is the core element of new media art. In the process of digital image production, all kinds of software are fully used. With the improvement of technology, the protection of historical and historical materials of opera art is imminent.

The art of opera not only can be recorded and conveyed by photography and photography, but also needs to be realized with the help of various digital techniques.One can use a 3D motion capture system, can be part of the drama interpretation changes timely recorded, thus the body motion capture details, although this product is still relatively simple, but it has been applied in different fields, in the creation of animation, film and television production are involved. Second, with the help of 3D scanning technology, the application of this technology can display three-dimensional images, improve the transfer of three-dimensional coordinates and color information, fully display the real characters, and even display the internal structure of objects. Compared with the traditional plane display, three-dimensional scanning is not only a display of pictures, but also a three-dimensional object. Not only to show the surface of an object, but to display the object in an all-round way.

The 3D scanning technique can be a real world with the help of three-dimensional way to show in front of the audience, the digital signal processing by computer, through the analysis of visual effects and virtual reality show, the actors and props completely displayed, combined with modern video image processing, expand, shrink, rotate on the image, make the image ratio more reasonable, in the image and certain scenes together[4].

The most essential function of the image is the recording, so in the part of the protection of the opera, it can be combined with the form of the film. Nowadays, people are not familiar with traditional opera, but they are very familiar with movies, TV and Internet. Therefore, combining opera and movie can better inherit drama literature and art.

\section{The spread of opera art in the new media era}

Nowadays, the transmission of information is based on the way of digital transmission, and the efficiency of information dissemination from publication to dissemination is enhanced by the combination of computer technology and network technology. These are all media that cannot be compared with the media.

First, information supply has unlimited characteristics. After the emergence of new media, information overload is mainly based on hypertext, and information transmission has nonlinear characteristics. Therefore, the way of information transmission is very flexible, and a diversified way of transmission. After the development of the new media, the dissemination of information is based on the hypertext format, and the spread of the new media is gradually expanding. Secondly, the transmission of information has the characteristics of interaction. In the transmission of information, it is no longer the way of one-way communication, and the audience can accept the information actively. The communication and reception of information have gradually emerged in the form of interaction. The interaction of information has some vivid characteristics, in information dissemination, its timeliness is improving, and the dissemination of information presents a clear sense of rhythm. In the information receiving link, the information can be evaluated by the platform, and the audience can receive the information that is more interested in it. Information transmission is more targeted. People can receive information more pertinent through interaction. For different groups of people, information disseminators can disseminate information with purpose. Nowadays, people can interact information through websites and multimedia. People can search information through Internet search engine. Under the development of new media technology, the dissemination of information has shown an infinite extension. Its traditional way of expression is integration and interaction, and the way of information expression is more vivid through new media technology. The future media will achieve a wide range of media integration to achieve human-computer interaction[5].

In the way of communication, more sensory stimulation can be generated for the audience. 
Compared with the traditional media, new media can release information in real time, and realize interactive features, and combine text, sound and picture together. In the spread of new media, the form of information is more abundant, and it will have a greater impact on the audience's psychology. In the media information, the main realization of the design of digital information, through the new media to spread to people. The content of information is more extensive, the capacity of information is larger, the input and output of information are more convenient, and meet people's communication. The new media information carrying text, images and graphics, mobilize the multi sensory audience, the traditional media have a mandatory feature, new media, people can voluntarily choose to receive their love of the information, and according to their own preferences to understand the content of the message. In the process of information processing, we can bring comprehensive perception effect to people, bring richer visual and auditory characteristics to people, and human brain is more flexible in information processing. In the amount of new media communication, visual symbols have an effective effect on people's understanding[6].

With the development of new media technology, people have entered a new information age. The speed of information dissemination is fast, and it is not restricted by any conditions. In the link of traditional opera communication, in the traditional way of communication, there are mainly stage communication, printing and broadcasting, radio and television transmission. Today, the Internet technology widely, the communication of traditional opera has a new camp, in the dissemination of new media, the communication of traditional opera has the support of information technology, the essence and the artistic characteristics of the opera's new media platform for the dissemination of the opera connotation re call.

Because of the new media has its own characteristics, the new media technology in the spread of opera, for the spread of drama into the new vitality. The dissemination of new media technology has enabled audiences to meet diverse needs, and opera lovers have been more convenient in collecting all kinds of opera information, breaking the limitation of time and space transmission, and making communication between audiences of traditional opera easier. The sharing and application of network resources make opera dissemination more effective. People can accept the influence of traditional opera culture through the Internet, which is conducive to the further development of opera art.

With the rapid development of Internet technology, the network can extend to all parts of the world, so the art of opera can also be spread all over the world. After continuous development, the form of the opera is gradually mature.

In the application of new media technology, the communication of opera can help the traditional media website's Opera resources. Nowadays, the Internet is developing rapidly, and the traditional media will start to start its own website with the help of network. In the traditional media, a lot of drama information will also appear on the Internet. These websites mainly have some newspapers and periodicals, and some websites have set up opera channels. Opera culture has also been spread in many educational institutions. Many schools in our country have built their own websites, which will be integrated into the opera culture. If the website of Academy of Chinese Traditional Opera has collected a lot of opera culture, many experts will also make their own views, which will provide a lot of information for drama learners. There are a lot of opera culture on a lot of comprehensive websites, and many comprehensive portal websites are very rich in information and use a large number of search engines.

The civilization of a country can be shown to a great extent through the museum. Through the analysis of the situation of the development of the museum, the museum not only collects a large number of cultural relics, but also collects a large amount of cultural information. China has not yet established the actual Opera Museum, the capital museum is also the study of Beijing opera. A large number of scripts and folk materials have been collected in the museum. In the collection of opera culture, the capital museum is restricted by geographical content and its content is relatively simple. Visitors often can't see all the materials they want to see. Therefore, in the future construction, museums should combine new media technology with multimedia presentation to achieve interactive communication, so that visitors can feel the connotation of opera art more 
comprehensively.

With the promotion of the protection of the intangible cultural heritage in China, the museum should bring forth new ideas. The traditional museum is restricted by the site, so many exhibits can not be displayed in all, and can only be displayed in a rotating way. In order to attract more people to visit the museum, digital technology should be used to show the full picture of the museum.

In digital art, animation art, which is closely related to it, can attract people of different ages. Digital art is the foundation in the development of digital animation on digital animation, also known as computer animation is the processing of graphics and images, generate a vivid picture of the software through the form of animation, will show a continuous static picture, showing a dynamic. Our country strongly advocates cultural creativity, and the development of animation industry is also very fast. Digital animation art has become a cutting-edge technology with the help of new media technology.

In the links of drama change, we should make full use of the new media to create a new way for the dissemination of opera art, so that teenagers can fully understand the charm of traditional opera art. The drama animation just rose, not very mature yet, but its effect is better. The history of animation industry in China has a long history, and the material of animation is very wide. In Chinese operas, Peking Opera and Kunqu Opera are important branches. Chinese opera culture also has a deep memorial ceremony. To a certain extent, it can promote the further development of China's animation industry. With vivid animated form, we can show the popular opera characters. After watching the animation, children can also fully understand the profound connotation of Chinese opera culture. They can also be imperceptibly edifying in watching the links of animation. Opera animation can be shown in animated series, and can also be displayed by FLASH. Such animations do not occupy much room for users, and the contents of many animations are very vivid.

\section{Conclusions}

Although new media technology can play a certain role in the inheritance of opera art, there are also some problems in its application. Many resources can not be fully utilized, and can not be well developed and utilized. Chinese opera websites are generally established by individuals, and the breadth of their communication is limited. The influence of new media in promoting the dissemination of opera art needs to be further improved. Drama is generally loved by the elderly, but young people do not like opera culture. However, most of the Internet users in China are young people, so there are limitations in the use of resources.

\section{References}

[1] Wen Lijun. The inheritance and protection of drama art from the perspective of new media, [J]. drama literature, 2016 (08): 74-76.

[2] Lu Bei. Based on the inheritance and protection of the opera art under the new media environment, the family of [J]. drama, 2015 (14): 23.

[3] Yang Yang. Protection and inheritance of opera art under the environment of new media [D]. Beijing Institute of Graphic Communication, 2007.

[4] Wang J J, Yao C M, Vniversity S N. Discussion on the Inheritance, Protection and Transformation of Shanxi Traditional Opera Culture Heritage_-Taking Shangdang Bayinhui as an Example [J]. Journal of Jincheng Institute of Technology, 2013.

[5] Liu M. The Inheritance and Development of Gui Opera from Perspective of the Reception Aesthetics [J]. Journal of Liuzhou Teachers College, 2013.

[6] Xun A, Zheng Q, Music S O, et al. Reflections on the Inheritance and Development of Local Operas in the Background of New Urbanization[J]. Journal of Huaihai Institute of Technology, 2016. 